\section{Heard above the hubbub}

\author{
R.W. Guillery
}

Encyclopedia of Neuroscience, Vols I and II. Edited by George Adelman.

Birkhäuser: 1987. Pp. 1,565. \$125, £110, SwFr. 248.
NEUROSCIENCE has been growing up fast. With the appearance of this encyclopaedia we are bound to ask whether the discipline has reached maturity and to enquire about its personality. The two heavy volumes provide useful clues, serving as would a celebration, where the character and the behaviour of the guests tell much about the person being honoured.

The most important and numerous guests at this party are from the Society for Neuroscience, which has for many years acted as a combination of nanny and fairy godmother, and she has brought many of her best friends. At first, it is difficult to see much order in the clamour of about 700 separate entries, each covering a page or two of double-column print. Everyone seems to be talking at once and many are talking about themselves rather than their subject. A quick survey made up of three separate samples, 15 entries per sample, showed mean autocitation indices of $0.4-0.5$ (author's citations/total citations). Some of the guests are talking to themselves, not because they choose to but because in neuroscience today no one has much time for listening.

Brodal (the elder) has come dressed as Polonius. He talks wisely about training — "It is apparently not realized ... that knowledge in neuroanatomy ... requires adequate training and experience" - - and about a proper sense of the past - "This an undeserved underestimation of our predecessors". He might be describing any one of many of the entries, but no one is listening, not even the editor and the 32 eminent members of the advisory board.

The major condescension to a historical past is a long, inaccurate list, entitled "Concise Biographies of Contributors to Progress in Neuroscience, $300 \mathrm{BC}$ to $\mathrm{AD}$ 1950 " and written from one narrow viewpoint. Many minor figures are included but, among others, Marchi, Retzius, Held, Auerbach, Mauthner, Probst, van Gehuchten and Ganser are omitted. Ramon y Cajal is entered as a “... Spanish master of histology. [He] described the retina (1894); applied the Golgi staining technique for myelin and drew (1909) elegant depictions of neurons". The error concerning the Golgi technique is trivial beside the misunderstanding of Cajal's contribution.

The methods of categorization and the choice of entries seem arbitrary. Some entries may have been chosen to give a disregard of previous knowledge reflects particular author a voice, not to cover a particular subject. Evidence for editorial supervision is sparse. Three entries on neuroanatomy show significant overlap. Neurophysiology is not represented. Now that almost everyone is filling cells and drawing them, is neurophysiology thought to be extinct? And does the past really not matter? Aplysia has four entries, primates and flies two each, while reptiles, honeybees, leeches, nematodes, octopus and Paramecium have one entry each. Cats, rats, mice and frogs must make do with scattered mentions. One entry on primates says almost nothing about the brain and would have done excellently in an encyclopaedia of comparative anatomy. An entry on the "Triune Brain" must have come from a companion volume on neuromythology.

These are superficial impressions. The two volumes include many stimulating and useful essays and cover much important contemporary material. I have used two methods for providing a more detailed evaluation of coverage. One was to use the books to respond to a student's enquiry about the diencephalic or telencephalic origin of the globus pallidus and pulvinar, which was part of a discussion of cell migration in general. The entry on basal ganglia did not help with the globus pallidus: pulvinar is not in the index. When the discussion broadened we were unable to find either the alar plate or the reeler mutant in the index. Later, I did stumble on this mutant in a fine summary of mutant studies by R. Sidman, and we found that $P$. Rakic provides an admirably accessible summary of his views on cell migrations and radial glia.

A second approach has been to look at topics I felt I knew well. The entry on the lateral geniculate nucleus was hard to find because the index is poorly organized. When found, it proved to be one of those written for the expert rather than the general reader. The ground rules are assumed, some of the most interesting aspects are omitted and when it comes to detail the entry is wrong in its description of the primate nucleus.

The mamillary bodies make but a brief appearance as a part of the Papez circuit. No caudal connections are mentioned. This may be adequate coverage of an obscure subject. The medulla oblongata is less obscure but just as poorly covered. According to one entry "... in all vertebrates [it] consists primarily of the nuclei of origin and termination of the 5 th through 12th cranial nerves". According to another, in reptiles it contains only the 9 th to 12 th nuclei. Both are wrong. The visual system in contrast, especially the cortex, but also the retina, receives interesting and competent coverage.

One can learn about the neurosurgical treatment of pain, the distributed nature of memory, the receptor concept of drug action, or robotics, and spend hours of fascinating reading. Only the most discriminating readers will be able to distinguish the fine vintage contributions from the ordinary or adulterated ones. Anyone who stays at the party will get a clear sense of excitement about the future, but they'll be lucky if they avoid a hangover.

R.W. Guillery is Dr Lee's Professor in the Department of Human Anatomy, University of Oxford, Oxford $O X 13 Q X, U K$

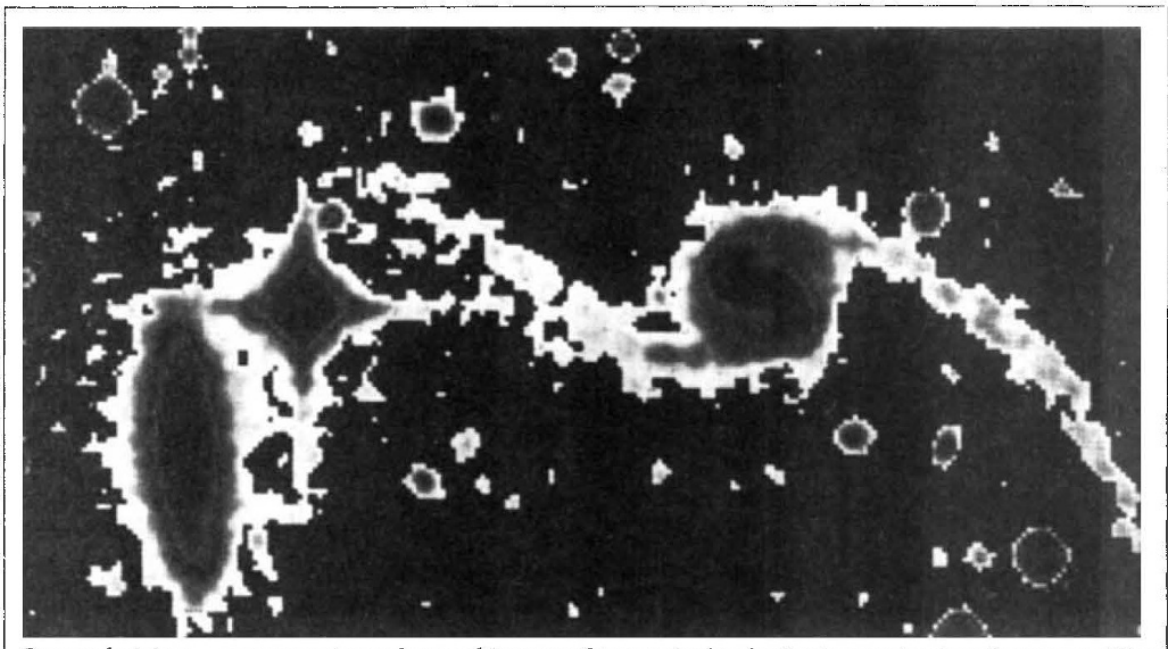

Beyond vision - a computer-enhanced image of two spiral galaxies in gravitational contact. The double system is enormous - IC 5174 (right), which has two long spiral arms, is 750,000 light years from tip to tip, and the galaxies have a radial velocity of 550 million light years. The picture is taken from Exploring the Southern Sky by Svend Laustsen, Claus Madsen and Richard M. West, just published by Springer-Verlag, price DM98 (DM128 in 1988). 